\title{
PENGARUH PENDIDIKAN KESEHATAN MELALUI VIDEO TERHADAP SELF-CARE MANAGEMENT PADA PASIEN DIABETES MELLITUS TIPE 2
}

\section{The Effect of Health Education Through Video on Self-Care Management in Type 2 Diabetes Mellitus Patients}

\author{
Ni Nyoman Suardani ${ }^{1}$, Putu Wira Kusuma Putra ${ }^{2}$, I.G. Agus Prasetya Krisna ${ }^{3}$ \\ ${ }^{I}$ Departemen Keperawatan Dasar dan Manajemen, STIKES Bina Usada Bali, Badung, Bali, Indonesia \\ ${ }^{2}$ Departemen Keperawatan Medikal Bedah, STIKES Bina Usada Bali, Badung, Bali, Indonesia \\ ${ }^{3}$ Rumah Sakit Daerah Mangusada, Badung, Bali, Indonesia \\ Korespondensi : putuwirakusumaputra@gmail.com
}

\begin{abstract}
ABSTRAK
Diabetes melitus merupakan penyakit kronik yang membutuhkan perawatan jangka panjang. Perawatan diri merupakan salah satu usaha pencegahan komplikasi dan menurunkan angka kematian pada diabetes mellitus. Self care management pada penderita diabetes melitus dapat ditingkatkan dengan memberikan pendidikan kesehatan, salah satunya melalui video. Penelitian ini bertujuan mengetahui adanya pengaruh pendidikan kesehatan melalui video terhadap self care management pada diabetes melitus tipe 2 di Poliklinik Interna RSD Mangusada Badung. Penelitian ini menggunakan rancangan pre eksperimental dengan desain one group pre-test and post-test. Jumlah sampel 37 responden dengan teknik pengambilan sampel menggunakan consecutive sampling. Data dikumpulkan menggunakan kuesioner summary of diabetes self-care activities. Data dianalisis menggunakan uji wilxocon. Hasil penelitian sebelum diberikan pendidikan kesehatan sebagian besar self care management cukup sebanyak 24 responden $(64.9 \%)$ terjadi peningkatan setelah diberikan pendidikan kesehatan sebagian besar self care management baik sebanyak 26 responden (70,3\%). Analisis pengaruh pendidikan kesehatan melalui video terhadap self care management pada diabetes melitus tipe 2 didapatkan nilai $\mathrm{p}<0,001$. Terdapat pengaruh pendidikan kesehatan melalui video terhadap self care management pada diabetes melitus tipe 2 . Rekomendasi penelitian ini diharapkan menjadi masukan bagi perawat agar selalu memberikan pendidikan kesehatan kepada penderita diabetes mellitus tipe 2 sehingga meningkatkan self care management pada diabetes
\end{abstract}

Kata kunci: pendidikan kesehatan, self care management, diabetes mellitus tipe 2

\section{ABSTRACT}

Diabetes mellitus is a chronic disease that requires long-term care. Self-care is an effort to prevent complications and reduce mortality in diabetes mellitus. Self-care management in diabetes mellitus sufferers can be improved by providing health education, one of which is through videos. This study aims to determine the effect of health education through video on self-care management of type 2 diabetes mellitus at the Internal Polyclinic RSD Mangusada Badung. This study used a pre-experimental design with a pre-test and post-test one group design. The number of samples was 37 respondents with consecutive sampling technique. Data were collected using a summary of diabetes self-care activitis questionnaire. Data were analyzed using the Wilxocon test. The results of the study before being given health education, most of the self-care management was sufficient as many as 24 respondents (64.9\%), there was an increase after being given health education, most of the self-care management was good as many as 26 respondents (70.3\%). Analysis of the effect of health education through video on self-care management in type 2 diabetes mellitus obtained $p$ value $<0.001$. There is an effect of health education through video on self-care management in type 2 diabetes mellitus. The recommendations of this study are expected to be an input for nurses to always provide health education to people with type 2 diabetes mellitus so as to improve self-care management in diabetes.

Keyword : health education, self care management, diabetes mellitus type 2 


\section{PENDAHULUAN}

Diabetes melitus (DM) merupakan salah satu penyakit yang banyak diderita oleh masyarakat di dunia (American Diabetes Association, 2014). Peningkatan angka insidensi dan prevalensi DM di berbagai penjuru dunia, badan kesehatan dunia WHO memprediksi adanya peningkatan jumlah penyandang DM yang menjadi salah satu ancaman kesehatan global (Soelistijo et al., 2015). American Diabetes Association (2014), menyatakan bahwa DM merupakan salah satu dari lima penyakit penyebab kematian terbesar. Meningkatnya angka komplikasi dan kematian salah satunya disebabkan karena kurangnya self care pada penderita DM (Kementerian Kesehatan RI, 2015).

Masyarakat di dunia pada tahun 2016 yang berumur di atas 18 tahun yang menderita DM mencapai 422 juta orang dengan prevalensi tertinggi di daerah Asia Tenggara dan Pasifik Barat (WHO, 2016). Data International Diabetes Federation (2017), prevalensi DM di dunia mencapai 424,9 juta jiwa dan diperkirakan akan mencapai 628,6 juta jiwa pada tahun 2045 (Cho et al., 2017). Indonesia merupakan negara dengan penderita DM terbanyak ke enam di dunia dengan jumlah penderita DM mencapai 10,3 juta jiwa. Diperkirakan angka tersebut akan terus mengalami kenaikan hingga mencapai 16,7 juta jiwa pada tahun 2045. Menurut data Badan Penelitian dan Pengembangan Kesehatan (2018), jumlah penderita DM di Indonesia sebanyak 1.017.290 orang dan Provinsi Bali dengan jumlah penderita DM sebanyak 16.481 jiwa. Penderita DM di RSD Mangusada Badung tahun 2018 sebanyak 9.600 jiwa.

DM memerlukan kontrol secara berkesinambungan untuk mencegah komplikasi jangka pendek dan jangka panjang (McGowan, 2011). Perawatan diri merupakan salah satu usaha pencegahan komplikasi dan menurunkan angka kematian pada DM (Kementerian Kesehatan RI, 2015). Pentingnya self care management pada penderita DM dapat mendorong pasien melakukan pencegahan dan pengobatan yang memerlukan kerja sama dengan petugas kesehatan sehingga mampu mengelola kesehatan secara mandiri (Sutandi, 2012).

Self care merupakan gambaran prilaku seorang individu yang dilakukan dengan sadar, bersifat universal, dan terbatas pada diri sendiri (Kusniawati, 2011). Self care yang dilakukan pada pasien DM meliputi pengaturan pola makan (diet), pemantauan kadar gula darah, terapi obat, perawatan kaki, dan latihan fisik (olah raga). Pasien DM lebih mengutamakan pengotrolan gula darah dan pencegahan komplikasi sehingga self care sangat penting bagi pasien DM, baik tipe 1 maupun tipe 2 (Kusniawati, 2011). Self care management melalui pendidikan kesehatan dapat meningkatkan individu memiliki rasa tanggung jawab terhadap kesehatan mereka sendiri dan memiliki peran yang penting terhadap perawatan kesehatan mereka sendiri (Bonnecwe, 2012).

Penelitian sebelumnya dilakukan oleh Sutandi (2012), mengemukakan self management education mempengaruhi peningkatan perawatan mandiri pasien dengan DM di rumah. Penelitian yang dilakukan oleh Pratama (2016), menunjukkan terdapat pengaruh yang signifikan antara pengetahuan dan sikap sebelum dan sesudah diberikan pendidikan kesehatan pada penderita DM.

Penatalaksanaan empat pilar DM yaitu edukasi, terapi gizi medis, latihan jasmani dan intervensi farmakologis. Penatalaksanaan DM dimulai dengan edukasi untuk mengubah gaya hidup dan perilaku pasien. Edukasi yang diberikan meliputi pemahaman tentang perjalan penyakit, pentingnya pengendalian dan pemantauan DM, penyulit dan resiko, intervensi farmakologis dan non farmakologis. Salah satu aspek yang memegang peranan penting dalam penatalaksanaan DM tipe 2 dengan pendidikan kesehatan atau edukasi kesehatan (McGowan, 2011). Pendidikan kesehatan pada penderita DM tipe 2 bertujuan meningkatkan pengetahuan dan keterampilan pasien sehingga memiliki perilaku preventif dalam gaya hidupnya untuk menghindari komplikasi DM jangka panjang (Pratama, 2016). 
Media pendidikan kesehatan salah satunya dengan media video. Media video merupakan media yang mudah difahami, modern dan menarik, dimana media ini mudah diterima. Media pendidikan dengan video memiliki kelebihann tersendiri yaitu mampu untuk menampilkan gambar yang bergerak, memiliki keunikan tersendiri yang tidak dimiliki media pembelajaran lainnya, konsep cerita dikemas menjadi pokok utama dalam pembelajaran dan materi yang panjang dan sulit disampaikan secara lisan dapat disajikan dalam bentuk film dan video yang mudah untuk dimengerti (Handayani \& Marniati, 2018).

Hasil studi pendahuluan yang dilakukan di poliklinik interna RSD Mangusada Badung pada tahun 2019 didapatkan data jumlah penderita DM tipe 2 pada lima bulan terakhir sebanyak 500 pasien. Dengan metode wawancara mengunakan kuesioner The Summary of Diabetes Self-Care Activities (SDSCA) terhadap 10 penderita DM tipe 2, didapatkan hasil tujuh orang dengan self care cukup dan tiga orang dengan self care kurang. Berdasarkan permasalahan tersebut penulis tertarik untuk melakukan penelitian tentang pengaruh pendidikan kesehatan melalui video terhadap Self care management pada DM tipe 2 di Poliklinik Interna RSD Mangusada Badung.

\section{TUJUAN PENELITIAN}

Tujuan dari penelitian ini adalah untuk mengetahui pengaruh pendidikan kesehatan melalui video terhadap self care management pada DM tipe 2.

\section{METODE PENELITIAN}

Desain

Design penelitian ini menggunakan rancangan pre eksperimental dengan pendekatan pre-test and post-test one group design (Sugiyono, 2016).

\section{Populasi dan Sampel}

Populasi dalam penelitian ini adalah semua pasien DM yang menjalani pengobatan di Poliklinik Interna RSD Mangusada Badung. Sampel pada penelitian ini memenuhi kriteria inklusi, seperti bersedia menjadi responden; bisa baca dan tulis; berusia 26-45 tahun. Sedangkan kriteria eksklusinya penderita DM tipe 2 yang mengalami komplikasi; emosinya tidak stabil; mengalami gangguan pendengaran. Besar sampel 37 responden dengan menggunakan consecutive sampling.

\section{Tempat dan Waktu Penelitian}

Penelitian dilakukan di Poliklinik Interna RSD Mangusada. Pengambilan data dan Pemberian Intervensi dilakukan selama 5 minggu.

\section{Intervensi}

Intervensi yang diberikan berupa pendidikan kesehatan berbasis video yang dikirimkan melalui aplikasi pesan singkat.Video pendidikan kesehatan diberikan 5 kali, dimana setiap minggu dikirimkan 1 video yang berdurasi 5 menit.

\section{Instrumen dan Prosedur Pengukuran}

Minggu pertama saat penderita DM kontrol ke poliklinik interna akan dilakukan penilaian self care management dengan mengunakan kuesioner SDSCA sebelum diberikan pendidikan kesehatan. Setelah 5 minggu diberikan intervensi, selanjutnya dilakukan penilaian kembali self care management dengan kuesioner SDSCA.

\section{Analisa Data}

Analisis data yang digunakan adalah uji wilxocon sign rank.

\section{HASIL PENELITIAN} berikut:

Hasil penelitian dijelaskan sebagai

\section{Tabel 1}

Pengaruh Pendidikan Kesehatan Melalui Video dengan Self Care Management pada Penderita Diabetes Mellitus Tipe $2(\mathrm{n}=37)$

\begin{tabular}{|c|c|c|c|c|c|}
\hline \multirow{2}{*}{ Variabel } & \multicolumn{2}{|c|}{ Pre-test } & \multicolumn{2}{|c|}{ Post-test } & \multirow{2}{*}{$\begin{array}{c}p \text { - } \\
\text { value }\end{array}$} \\
\hline & f & $\%$ & f & $\%$ & \\
\hline Baik & 4 & 10,8 & 26 & 70,3 & \\
\hline Cukup & 24 & 64,9 & 11 & 29,7 & 0.001 \\
\hline Kurang & 9 & 24,3 & 0 & 0 & \\
\hline
\end{tabular}

Hasil penelitian menunjukan sebagian besar self care management sebelum 
diberikan edukasi berada pada kategori cukup $(64,9 \%)$. Setelah diberikan edukasi melalui video sebagian besar self care management berada pada kategori baik (70.3\%). Selain itu, uji hipotesis menunjukkan ada pengaruh pendidikan kesehatan melalui video terhadap self care management pada penderita DM dengan niai $p=0,001(<0,05)$.

\section{PEMBAHASAN}

Hasil penelitian ini sejalan dengan penelitian(Dody Setyawan, 2015) yang menyebutkan kepatuhan diet DM sebelum diberikan pendidikan kesehatan pada penderita diabetes mellitus adalah patuh sebanyak 3 orang $(10 \%)$, tidak patuh 12 orang $(40 \%)$. Selain itu penelitian Pratama (2016) menyebutkan penderita DM yang diberikan pendidikan kesehatan memiliki sikap yang baik kemudian dikuti dengan sikap sedang dan yang terakhir sikap buruk. Selain itu, sebelum diberikan pendidikan kesehatan pasien memiliki self care management yang kurang sesuai dengan temuan penelitian (Putri, 2017).

Self care management yang cukup pada penderita DM tipe 2 sebelum diberikan pendidikan kesehatan melalui video dapat disebabkan kurangnya pemahaman tentang perawatan diri dirumah. Saragih (2010), mengemukakan, kurangnya informasi akan mempengaruhi self care management dimana self care management melibatkan perilaku mencegah keparahan (self care maintenance) dan melibatkan proses pengambilan keputusan dimana pasien mampu mengevaluasi dan mengatasi gejala penyakit ketika terjadi (self care management).

Beberapa faktor yang perlu diperhatikan agar pendidikan kesehatan dapat mencapai sasaran yaitu pendidikan. Beberapa faktor yang perlu diperhatikan agar pendidikan kesehatan dapat mencapai sasaran yaitu pendidikan. Putri (2017) menemukan sebagian besar pasien dengan pendidikan tinggi memiliki pengaruh terhadap perilaku self care management pada penderita DM. Seseorang yang memiliki pendidikan tinggi biasanya memiliki banyak pengetahuan tentang kesehatan sehingga individu dengan pendidikan tinggi cenderung memiliki self care baik.

Perawat yang bretindal sesuai peran sebagai educator pada pasien dan keluarga dapat memanfaatkan media video sebagai model edukasi. Edukasi mempengaruhi sikap serta ketrampilan orang lain, baik individu, kelompok, atau masyarakat, sehingga melakukan apa yang diharapkan pendidik. Perawat harus mampu memberikan edukasi kesehatan dalam pencegahan penyakit, pemulihan, penyusunan program pendidikan kesehatan serta memberikan informasi yang tepat tentang kesehatan. Untuk itu perawat harus memiliki pemahaman terhadap prinsipprinsip pengajaran dan pembelajaran (Soelistijo et al., 2015).

Pemanfaatan media audio visual sebagai perantara dapat membangun pengetahuan, keterampilan, atau sikap. Media pembelajaran interaktif atau interactive video adalah suatu sistem penyampaian pengajaran yang menyajikan materi video rekaman dengan pengendalian komputer kepada penonton yang tidak hanya mendengar dan melihat video dan suara, tetapi juga memberikan respon yang aktif, dan respon itu yang menentukan kecepatan dan efesiensi penyajian (Arsyad, 2009).

\section{KESIMPULAN}

Implikasi

Penelitian ini menunjukkan terdapat pengaruh pendidikan kesehatan melalui video terhadap self care management pada diabetes melitus tipe 2. Pemanfaatan tekhnologi menjadi sebuah tantangan baru dan peluang dalam pelaksanaan pendidikan kesehatan. Perawat sebagai educator dapat memanfaatkan layanan asuhan keperawatan berbasis tekhnologi dengan menerapkan pendidikan kesehatan melalui video.

\section{Keterbatasan}

Penelitian ini memiliki kelemahan, dimana peneliti tidak dapat memastikan video edukasi diputar ataupun disaksikan lagsung meskipun pada aplikasi yang 
digunakan terdapat notifikasi penyampaian pesan video terkirim. Dibutuhkan pengembangan model tekhnologi yang dapat menyempurnakan kelemahan dari penelitian ini di masa yang akan datang, sehingga pemanfaatan tekhnologi yang terbatas jarak tidak menurunkan kualitas layanan keperawatan.

\section{DAFTAR PUSTAKA}

American Diabetes Association. (2014). Diagnosis and classification of diabetes mellitus. Diabetes Care, 37(1), 81-90.

Arsyad, A. (2009). Media Pembelajaran. Jakarta: Raja Grafindo Perkasa.

Badan Penelitian dan Pengembangan Kesehatan. (2018). Hasil Utama RISKESDAS 2018. Jakarta.

Bonnecwe, E. T. (2012). Self care and patients with hypertension at primary health care clinics. Nort-West University.

Cho, N. H., Kirigia, J. M., Claude, J., Ogurstova, K., Guariguata, L., Rathmann, W., ... Esteghamati, A. (2017). IDF Diabetes Atlas. IDF Diabetes Atlas, 8th edition (8th ed.). Brussels: International Diabetes Federation.

Handayani, S., \& Marniati. (2018). Penerapan Media Video Pembelajaran Pada Kompetensi Dasar Membuat Pola Rok Secara Konstruksi Di Kelas X Tata Busana 3 SMK Negeri 6 Surabaya. E-Journal Universitas Negeri Surabaya, 07(02), 18-21.

International Diabetes Federation. (2017). IDF Diabetes Atlas, 2017. International Diabetes Federation. IDF Diabetes Atlas, 8th edn. Brussels, Belgium: International Diabetes Federation, 2017.

Kementerian Kesehatan RI. (2015). Profil Kesehatan Indonesia 2014. Jakarta: Kementerian Kesehatan Republik Indonesia.

Kusniawati. (2011). Analisis Faktor yang Berkontribusi Terhadap Self Care Diabetes pada Klien Diabetes Melitus Tipe 2 di Rumah Sakit Umum Tangerang. Universitas Indonesia.
McGowan, P. (2011). The efficacy of diabetes patient education and selfmanagement education in type 2 diabetes. Canadian Journal of Diabetes, 35(1), 46-53.

Pratama, P. A. (2016). Pengaruh Pendidikan Kesehatan Terhadap Pengetahuan dan Sikap Pasien tentang Pengelolaan Diet Diabetes Mellitus di Puskesmas Boyolali I. Universitas Muhammadiyah Surakarta.

Putri, R. L. (2017). Gambaran Self Care Penderita Diabetes Melitus Si Wilayah Kerja Puskesmas Srondol Semarang. Universitas Diponegoro.

Saragih, F. S. (2010). Pengaruh Penyuluhan Terhadap Pengetahuan dan Sikap Ibu Tentang Makanan Sehat dan Gizi Seimbang di Desa Merek Raya Kecamatan Raya Kabupaten Simalungun Tahun 2010. Universitas Sumatera Utara.

Soelistijo, S., Novida, H., Rudijanto, A., Soewondo, P., Suastika, K., Manaf, A., ... Soetedjo, N. (2015). Konsesus Pengelolaan Dan Pencegahan Diabetes Melitus Tipe2 Di Indonesia 2015. Perkeni.

Sugiyono. (2016). Metode Penelitian Pendidikan (Pendekatan Kualitatif, Kuantitaif, R\&D) (Revisi). Bandung: Alfabetha.

Sutandi, A. (2012). Self Management Education (DSME) Sebagai Metode Alternatif Dalam Perawatan Mandiri Pasien Diabetes Melitus di Dalam Keluarga. Widya, 29(321).

WHO. (2016). 10 facts on diabetes. Retrieved from https://www.who.int/ features/factfiles/diabetes/en/ 